\title{
LAS MIGRACIONES INTERIORES Y EXTERIORES EN EL MAGREB: REPERCUSIONES DEMOGRÁFICAS, SOCIECONÓMICAS Y MEDIOAMBIENTALES
}

\author{
D. ${ }^{a} M^{a}$ Angeles Morán Rodriguez y Dr. D. Ángel Navarro Madrid \\ Universidad Complutense de Madrid. España
}

\section{INTRODUCCIÓN}

La segunda mitad del siglo XX ha visto, como consecuencia o en relación con los acontecimientos políticos y económicos que la caracterizan, como las poblaciones asentadas durante generaciones en su propio territorio se veían impulsadas a migrar. Los flujos de personas que se han producido así están cambiando el mundo y, sobre todo, están cambiando los países emisores o receptores de esta población expatriada de su lugar de origen.

Mientras las primeras décadas de este medio siglo se nutren principalmente de emigrantes forzosos, en razón de ajustes territoriales, creación de nuevos estados, cambios políticos radicales, expulsiones o simple huida de la persecución y el terror, las últimas décadas presentan un carácter diferente en la emigración.

En efecto, en estos últimos años, especialmente tras la desaparición de la bipolaridad política mundial y el hundimiento del sistema comunista a escala global, y del que la caída del Muro de Berlín en 1989 fue el primer acto importante. También es una emigración forzada, ya que las condiciones de miseria, pobreza o falta de perspetivas - no sólo económicas, también la libertad política o de desarrollo social-, tanto para los adultos como para los hijos de éstos, les ha llevado a abandonar su lugar de origen y desplazarse hacia otros lugares, ya sea dentro del pais, ya fuera de él.

Es una emigración siempre dolorosa, pero especialmente cuando se trata de una emigración campesina, ya que agricultores y ganaderos poseen unos modos de vida vinculados a la tierra y a un entorno geográfico individualizado, original y muy diferente al que encontrarán al final de su viaje en busca de mejores perspectivas.

Decimos que gran parte de esta población queda desarraigada, en países ajenos o en medios urbanos tan diferentes del que proceden, y el símil agrario es real, pues poseen unas raíces muy marcadas, una comunión con su medio geográfico que resulta dificil de entender con parámetros "urbanitas". 
Sin embargo el volumen de población que rápidamente va nutriendo estos flujos migratorios nos habla del grado de abandono, de desesperación y de fuerza resolutiva que les anima. Es una fuerza imparable que les lleva a intentar una y otra vez acceder a un mundo, el llamado mundo desarrollado, que les ofrece lo que no poseen en su país -a veces la mera subsistencia- pagando un altísimo coste. Se pueden incentivar, permitir o frenar estos movimientos migratorios, se les puede incluso prohibir, pero no se les puede impedir, porque la fuerza de la desesperación romperá todas las barreras que se les pongan o encontrará resquicios por donde pasar.

La marcha del campo a la ciudad y la emigración hacia los paises de la Europa desarrollada, tan característicos de España durante los años 60 y 70 , se dan ahora a una escala infinitamente superior en diferentes partes del mundo y siempre en los países subdesarrollados o en transición.

Los gigantescos flujos migratorios interiores de algunos paises han creado megaciudades como Shangai, Tientsin, Pekín o Cantón, en China; Bombay o Calcuta, en la India; Seúl, en Corea; Yakarta, en Indonesia; Karachi, en Pakistán; Dacca, en Bangla Desh; Manila, en Filipinas; El Cairo, en Egipto; Lagos, en Nigeria; Ciudad de México, en México; Lima, en Penú; Buenos Aires, en Argentina o Sao Paulo y Río de Janeiro, en Brasil. Son ciudades que tienen más de 10 millones de habitantes, o los alcanzarán en los próximo años (algunas llegarán a tener en el 2010 más de 20 millones de habitantes) y a esta característica de rango demográfico se le añaden otras, como poseer un crecimiento vertiginoso y escasos o nulos planes que permitan la acogida de estas masas de desplazados de las áreas rurales.

Por otro lado, determinados paises o áreas desarrolladas son el horizonte y destino para masas importantes de población. Éste es el caso de Estados Unidos o los países de la Unión Europea. La frontera sur de Estados Unidos, especialmente el límite con México es la puerta soñada para millones de centroamericanos y suramericanos, además de otros grupos (asiáticos, europeos del Este, etc.). En nuestro caso, con independencia de la amplia zona oriental europea por la que penetran los grupos procedentes del antiguo bloque comunista, destaca el papel de los dos puntos donde el Mediterráneo se estrecha y aproxima a Europa y África: Gibraltar y Sicilia.

Gibraltar ha sido a lo largo de la historia, tanto geológica como humana, un paso, un puente entre los dos continentes. También, en ocasiones, debido a enfrentamientos políticos o religiosos, ha sido una valla, un foso que separaba ambos espacios. Hoy que la tecnología, la cooperación, la mundialización de la economía podrían hacer de Gibraltar un puente más real, más útil y dinámico que nunca, se ha transformado en una especie de fielato, de barrera que permite los flujos entre ambas partes con cuentagotas. Porque Europa es la interesada en mantener esta puerta solo entreabierta, marcando las cantidades de personas, los tipos de intercambios, que se pueden hacer, en razón de sus intereses.

Frente a este hecho se agolpan en la orilla africana personas, necesidades, sueños, que una y otra vez insisten en romper este filtro y acceder a mejores condiciones de vida 0 vida simpelemente, garantizar la existencia -propia y de las personas que han dejado en sus lugares de procedencia- a costa de los esfuerzos y sacrificios que sean necesarios. 
El Magreb, especialmente en los años 90, y más concretamente desde 1997, se ha convertido en una plataforma privilegiada para acceder a la Unión Europea. La población magrebi, especialmente marroquies, pero también argelinos y, en mucha menos proporción tunecinos, se agolpan en los puntos más próximos a España (o Italia) para poder pasar al continente europeo, bien con contratos de trabajo en una emigración controlada y asistida, legal, o, las más de las veces, a través de ese fenómeno, no solo demográfico, sino social y económico que son las "pateras", las rudimentarias embarcaciones que constituyen el vehiculo de acceso al mundo desarrollado o a la muerte, debido a las precarias condiciones de éstas.

$\mathrm{Y}$ junto a esta población indígina se encuentra, cada vez en mayor número, la procedente de otras áreas africanas, especialmente del África saheliense y guineana, con unas condiciones económicas, sociales y politicas en sus países de origen aún peores que las norteafricanas, y que ponen en esta emigración su única tabla de salvación. Así, las áreas próximas al estrecho de Gibraltar, o a la costa canaria son como grandes campos de concentración listos para el desembarco, intermitente pero continuado, de esta población. Población que, por otra parte, dado que no tiene nada que perder salvo la vida, hará cuantos intentos sean necesarios, una y otra vez, hasta alcanzar su objetivo. La politica de poner vigilancia y controlar los viajes y a los agentes de este tráfico infernal es como poner parches para detener una sangría genera: no es la solución y, probablemente, ni siquiera es una solución, sólo un freno temporal y esporádico.

\section{LA DINÁMICA MIGRATORIA DEL MAGREB EN LOS ÚLTIMOS AÑOS}

Es evidente, que cualquier estudio demográfico de un país, región o lugar, aunque sea de carácter temático o específico, como es el fenómeno migratorio, tiene que tener en cuenta el comportamiento general de la población. La dinámica migratoria, como la natural, posee aspectos relevantes o concretos, pero siempre referidos al conjunto de la población, su evolución y estructura. Por ello, es imprescindible tener en cuenta cuál ha sido la evolución histórica de la población magrebí y, también, determinar cuál sea su previsible desarrollo futuro.

El cuadro I nos muestra esa evolución entre 1970 y el año 2000, así como la densidad general. En este periodo se aprecia, por encima de las escasas diferencias existentes entre cada pais, que el conjunto de la región ha visto duplicarse su población en estos 30 años. $\mathrm{Si}$ atendemos a la densidd general es preciso hacer notar que no incluye el Sahara Occidental, anexionado por Marruecos en varias etapas, a partir de 1975, y que todavía no presenta un status internacional reconocido. Su extensión, unos $250.000 \mathrm{~km}^{2}$, algo más que la mitad del propio Marruecos, reduciría notablemente la densidad del conjunto que aparece en el citado cuadro 1, ya que su población no llega a los 300.000 habitantes. También cabe citar que parte de la población autóctona abandonó el territorio cuando se produjo la incorporación a Marruecos, ubicándose en el extremo suroeste de Argelia, en los campamentos de refugiados de Tindouf, a la espera de una solución pacifica para la región. 


\section{Cuadro 1}

Evolución histórica de la población y la densidad del Magreb

\begin{tabular}{|c|c|c|c|c|}
\hline & ARGELIA & MARRUECOS(1) & TÚNEZ & TOTAL \\
\hline 1970 & 14,33 m. h. $\left(6,0 \mathrm{~h} / \mathrm{km}^{2}\right)$ & $15,31 \mathrm{~m}$.h. $\left(33,3 \mathrm{~h} / \mathrm{km}^{2}\right)$ & $5,13 \mathrm{~m} . \mathrm{h} \cdot\left(31,3 \mathrm{~h} / \mathrm{km}^{2}\right)$ & 34,77 m. h. $\left(11,6 \mathrm{~h} / \mathrm{km}^{2}\right)$ \\
\hline 1975 & $16,78 \mathrm{~m} . \mathrm{h} \cdot\left(7,0 \mathrm{~h} / \mathrm{km}^{2}\right)$ & $17,31 \mathrm{~m}$. h. $\left(37,7 \mathrm{~h} / \mathrm{km}^{2}\right)$ & $5,61 \mathrm{~m}$. h. $\left(34,2 \mathrm{~h} / \mathrm{km}^{2}\right)$ & 39,70 m. h. $\left(13,2 \mathrm{~h} / \mathrm{km}^{2}\right)$ \\
\hline 1980 & $18,67 \mathrm{~m}$. h. $\left(7,8 \mathrm{~h} / \mathrm{km}^{2}\right)$ & $20,05 \mathrm{~m} . \mathrm{h} \cdot\left(43,7 \mathrm{~h} / \mathrm{km}^{2}\right)$ & $6,39 \mathrm{~m}$. h. $\left(39,0 \mathrm{~h} / \mathrm{km}^{2}\right)$ & $45,11 \mathrm{~m}$. h. $\left(15,0 \mathrm{~h} / \mathrm{km}^{2}\right)$ \\
\hline 1985 & 21,85 m. h. $\left(9,2 \mathrm{~h} / \mathrm{km}^{2}\right)$ & $21,84 \mathrm{~m}$. h. $\left(47,6 \mathrm{~h} / \mathrm{sm}^{2}\right)$ & $7,26 \mathrm{~m}$. h. $\left(44,3 \mathrm{~h} / \mathrm{km}^{2}\right)$ & 50,95 m. h. $\left(17,0 \mathrm{~h} / \mathrm{km}^{2}\right)$ \\
\hline 1990 & $25,02 \mathrm{~m} . \mathrm{h} \cdot\left(10,5 \mathrm{~h} / \mathrm{km}^{2}\right)$ & $24,49 \mathrm{~m}$. h. $\left(53,4 \mathrm{~h} / \mathrm{km}^{2}\right)$ & $8,15 \mathrm{~m}$. h. $\left(49,7 \mathrm{~h} / \mathrm{km}^{2}\right)$ & 58,66 m. h. $(19,6$ h/km²) \\
\hline 1995 & $28,06 \mathrm{~m} . \mathrm{h} .\left(11,8 \mathrm{~h} / \mathrm{km}^{2}\right)$ & 27,11 m. l. $\left(59,1 \mathrm{~h} / \mathrm{km}^{2}\right)$ & 8,96 m. h. $\left(54,6 \mathrm{~h} / \mathrm{km}^{2}\right)$ & $64,13 \mathrm{~m} . \mathrm{h} \cdot\left(21,4 \mathrm{~h} / \mathrm{km}^{2}\right)$ \\
\hline 1997 & 29,47 m. h. $\left(12,4 \mathrm{~h} / \mathrm{km}^{2}\right)$ & $28,13 \mathrm{~m}$. h. $\left(61,3 \mathrm{l} / \mathrm{km}^{2}\right)$ & 9,22 m. h. $\left(56,2 \mathrm{~h} / \mathrm{km}^{2}\right)$ & 66,82 m. h. $\left(22,3 \mathrm{~h} / \mathrm{km}^{2}\right)$ \\
\hline 2000 & 31,5 m. h. $\left(13,2 \mathrm{~h} / \mathrm{km}^{2}\right)$ & 28,8 m. h. $\left(62,7 \mathrm{~h} / \mathrm{km}^{2}\right)$ & $9,6 \mathrm{~m}$. h. $\left(58,5 \mathrm{~h} / \mathrm{km}^{2}\right)$ & 69,9 m. h. $\left(23,3 \mathrm{~h} / \mathrm{km}^{2}\right)$ \\
\hline \multicolumn{5}{|c|}{$\begin{array}{l}\text { (1) Excluido el Sahara Occidental. } \\
\text { Fuente: Anuario estadística de la UNESCO } \\
\text { World Data Sheet }\end{array}$} \\
\hline
\end{tabular}

Todo esto arroja finalmente una población actual de unos 70 millones de habitantes y una densidad global de $23,3 \mathrm{hab} / \mathrm{km}^{2}$. Sin embargo, aún con las diferencias regionales que existen en cada país, los tres poseen un rasgo distintivo que gravita sobre todas las actividades del pais y también sobre la población, su distribución y densidad: el desierto.

En efecto, la presencia del Sahara, sus caracteres extremados, las limitaciones radicales que impone a la actividad humana o condiciones para que ésta se desarrolle, es el principal factor que explica una disimetria poblacional.

Argelia se organiza administrativamente en 30 wilayas, de las que las 9 cuyo territorio forma parte del Sahara, ocupan casi $2.109 .000 \mathrm{~km}^{2}$ ( $88 \%$ de la población nacional), pero sólo tienen una población de 1,6 millones de habitantes ( $5 \%$ de la población total), con una densidad media de $0,7 \mathrm{hab} / \mathrm{km}^{2}$. Más aún, un tercio de dicha población se asienta en las capitales de cada wilaya, por lo que podemos decir que también poblacionalmente es un desierto. La densidad real de Argelia, si tuviéramos en cuenta sólo la parte norte del pais, en gran medida montañosa o de transición al desierto, sería por tanto no los $12,6 \mathrm{hab} / \mathrm{km}^{2}$ que reflejan las cifras oficiales, sino unos $120 \mathrm{hab} / \mathrm{km}^{2}$, y 7 wilayas, además de la capital, Argel, superan los $300 \mathrm{hab} / \mathrm{km}^{2}$.

En Marruecos la parte perteneciente al Sahara es más reducida, pero las 6 provincias (de un total de 35) que tienen en él su territorio, en mayor o menor medida, suponen unos $234.000 \mathrm{~km}^{2}$, es decir, la mitad de la superficie del país, mientras que la población apenas llega a 1,6 millones de habitantes (5,5\% del total). Mientras que la densidad media de estas provincias no llega a $7 \mathrm{hab} / \mathrm{km}^{2}$, la nacional se establece en $62,7 \mathrm{hab} / \mathrm{km}^{2}$, y 10 provincias, además de las dos prefecturas de Casablanca y Rabat-Salé, superan los $150 \mathrm{hab} / \mathrm{km}^{2}$.

Aunque la distribución de la población es más homogénea en Marruecos que en Argelia y tiene menor presencia al desierto de Sahara, la cordillera del Atlas, que aqui alcanza sus 
máximas alturas (Toubkal, $4164 \mathrm{~m}$.), supone un obstáculo para la presencia humana y la actividad económica.

Túnez, por último, presenta unos caracteres mixtos, ya que mientras la mitad del norte es accidentada, al encontrarse aquí las últimas estribaciones de la cordillera del Atlas, la mitad sur es puro desierto o está ocupada por enormes "chotts" o lagos salados, como el Djerid, con más de $100 \mathrm{~km}$. de longitud y hasta $50 \mathrm{~km}$. de anchura. Las tres gobernaciones (provincias) del desierto, Kebili, Tatauin y Tozeur, ocupan unos $65.000 \mathrm{~km}^{2}(40 \%$ de la superficie nacional) y unos 360.000 habitantes $\left(5,5 \mathrm{hab} / \mathrm{km}^{2}\right)$. La densidad media es de 58,5 $\mathrm{hab} / \mathrm{km}^{2}$, y en 8 de las 23 gobernaciones se superan los $150 \mathrm{hab} / \mathrm{km}^{2}$.

En definitiva, aunque tradicionalmente la población se ha concentrado en la mitad norte de la región magrebí, especialmente en las áreas costeras y también en las cuencas fluviales y las depresiones regadas del interior, en los últimos decenios este proceso se ha acelerado y potenciado, de tal modo que si la población urbana en 1970 suponía poco más del $40 \%$, hoy llega ya al $58 \%$.

En 1950 la población total del Magreb era de 21,1 millones de habitantes (Argelia, 8,75 millones; Marruecos, 9,95 millones y Túnez, 3,53 millones). Hoy el total roza los 70 millones de habitantes, y los porcentajes de crecimiento en este medio siglo son del $360 \%$ para Argelia, del 322\% para Marruecos y del $272 \%$ para Túnez, con una media para la región del $329 \%$. Todo esto viene propiciado por unas tasas muy altas para la natalidad -frenada en los últimos diez años-, una reducción acusada de la mortalidad y unas pérdidas migratorias que sólo han sido importantes numéricamente en la última decena de años. Las proyecciones de la población para el año 2025 nos hablan de una población magrebí de 100 millones de habitantes (equivalentes a la población de Italia, España y Portugal en la misma fecha), lo que nos habla de la importancia demográfica -y también económica, política, etc.- de esta región.

El proceso de concentración urbana, aunque notorio, no ha alcanzado aún su cénit y cabe esperar un rápido y mayor incremento de la población urbana. especialmente de aquellas áreas que gozan de posiciones estratégicas, sobre todo en los puertos mediterráneos y atlánticos y las que suponen centros neurálgicos de comunicaciones. La industria, el comercio y el turismo se concentran en estas áreas y, dado que estas actividades son las más dinámicas y las que ofrecen un mayor número de empleos (junto a la construcción y los servicios), está claro que se creará una red jerárquica de ciudades que supondrá más de la mitad de la población de cada país y de la aportación al P.I.B. En estos momentos ya es posible apreciar este proceso de concentración urbana, tal como se pone de manifiesto en la evolución de la población en los principales centros urbanos de la región (Cuadro n.”2).

Las principales metrópolis supranacionales son Casablanca (3,5 millones) y Rabat-Salé (1,5 millones) en Marruecos; Argel (2,5 millones) en Argelia y Túnez ( 1 millón) en su propio país. Un segundo nivel, el de las ciudades que ejercen un papel importante, a escala nacional, son las que cuentan con más de medio millón de habitantes: Orán y Constantina, en Argelia, y Marrakech, Fez y Meknes, en Marruecos. Finalmente, un tercer grupo de ciudades, con menor población, juegan un papel regional, atrayendo la población de su entorno y organizando unos espacios regionales o comarcales. 
Como ya se ha dicho, la localización preferente es costera, como ocurre con 14 de las 21 ciudades que figuran en el cuadro $n^{0} 2$.

\section{Cuadro 2}

Las ciudades del Magreb

\begin{tabular}{|lrrr|}
\hline ARGELIA & 1966 & 1977 & 1997 \\
\hline Annaba & 152.000 & 256.000 & 320.000 \\
\hline Argel & 944.000 & 1.722 .000 & 2.562 .000 \\
\hline Constantina & 244.000 & 354.000 & 481.000 \\
\hline Orán & 327.000 & 492.000 & 680.000 \\
\hline Setif & 88.000 & 144.000 & 240.000 \\
\hline MARRUECOS & 1971 & 1982 & 1997 \\
\hline Casablanac & 1.506 .000 & 2.139 .000 & 3.212 .000 \\
\hline Fez & 325.000 & 449.000 & 775.000 \\
\hline Marrakech & 333.000 & 440.000 & 746.000 \\
\hline Meknes & 248.000 & 320.000 & 450.000 \\
\hline Oujda & 176.000 & 260.000 & 679.000 \\
\hline Rabat-Salé & 530.000 & 1.020 .000 & 1.484 .000 \\
\hline Safi & 129.000 & 197.000 & 210.000 \\
\hline Tanger & 188.000 & 188.000 & 240.000 \\
\hline Tetuán & 139.000 & 200.000 & 278.000 \\
\hline Tú́NEZ & 1966 & 1984 & 1994 \\
\hline Ariana & 22.000 & 99.000 & 153.000 \\
\hline Bizerta & 52.000 & 95.000 & 140.000 \\
\hline Gabes & 32.000 & 92.000 & 125.000 \\
\hline Kairuán & 46.000 & 72.000 & 103.000 \\
\hline Sfax & 70.000 & 232.000 & 282.000 \\
\hline Susa & 58.000 & 84.000 & 125.000 \\
\hline Túnez & 648.000 & 774.000 & 899.000 \\
\hline Fuente: Calendario Atlante de Agostini & & \\
\hline & & & \\
\hline & & & \\
\hline
\end{tabular}

En Argelia sólo Constantina y Sétif se encuentran en el interior, mientras en Marruecos los valles interiores, regados por ríos que descienden del alto Atlas, como el Muluya, el Sus, el Tensift y el Sebú, acogen a ciudades de gran importancia histórica y cultural (y también artística y, por lo tanto, turistica), como Fez, Marrakech, Meknes y Oujda. Finalmente, en 
Túnez, sólo Kairuán, centro religioso (se considera la cuarta ciudad santa del Islam) y capital histórica de la dinastía aglabí, se encuentra en el interior del país.

Las migraciones exteriores son, sin embargo, las que han dado notoriedad al proceso, a pesar de no poseer el volumen que tiene las interiores, ni tampoco las repercusiones y cambios que provocan en cada uno de los países de origen.

$\mathrm{Si}$ atendemos a la población magrebi residente en los países de la Unión Europea, destino prioritario de esta región, apreciaremos la aceleración del proceso, por otr aparte bastante localizado espacialmente.

En 1990 existían unos 2,5 millones de magrebies en la U. E., de los cuales 1,4 millones se redicaban en Francia, principal país receptor de estos emigrantes, tanto por su vinculación con la región como antigua metrópoli colonial, como por las facilidades idiomáticas, su capacidad e interés en estos flujos de mano de obra barata y su carácter abierto a la acogida de refugiados políticos o sociales. De esta cantidad, unos 620.000 eran argelinos (sobre un total de unos 650.000 inmigrantes, de esa nacionalidad en Europa), 208.000 tunecinos (de 285.000 emigrantes en total).

En 1994 los argelinos en la U.E. eran unos 650.000, principalmente en Francia $95 \%$ del total) y solo unos 23.000 en Alemania. Actualmente las cifras están en el entorno de los $3 / 4$ de millón, pero cada vez llegan más, por razones políticas, huyendo de una guerra civil o de matices religiosos que ha diezmado la población, amenazado la quiebra de las instituciones y ha provocado la huida hacia las áreas urbanas, algo más seguras, de componentes numerosos de población rural, agotada por las estériles y salvajes matanzas indiscriminadas.

En cuanto a Marruecos, en 1994 había algo más de 1,1 millones en Europa, siendo Francia (573.000), Holanda (165.000), Bélgica (145.000), Alemania (83.000), Italia (77.000) y España (64.000) los principales destinos. Sin embargo, en los últimos años España es el país que más rápidamene ha visto crecer el número de marroquíes emigrantes. Sin en 1986 sólo había 8.600 marroquíes en España, en 1991 se llegó a casi 50.000 y 77.200 en 1996, último año de un aumento lineal pero moderado.

A partir de este año las cifras se disparan y pasan de 111.100 marroquíes en España en 1997 (18,2\% de los emigrantes) hasta más de 200.000 en la actualidad. El presente año, especialmente, ha visto una llegada masiva de emigrantes, tanto a través de una emigración legal como el ininterrumplido flujo de pateras que ha llegado al sur de españa y, recientemente, Canarias, especialmente entre Junio y Septiembre, convirtiéndose en un acontecimiento social y un aldabonazo hacia nuestras conciencias por las escenas y los casos, casi siempre trágicos, que justifican esta desesperante aventura.

Túnez no posee unos volúmenes tan importantes y, además, la generación de puestos de trabajo por un floreciente turismo, así como la construcción y una industria un tanto obsoleta, ha frenado esta marcha hacia el exterior, pero ha acentuado la marcha desde el interior a la costa. En 1994 habia unos 206.000 tunecinos, en Francia, 35.000 en Italia (su vecino inmediato) y 28.000 en Alemania. Hoy la emigración tunecina en Europa consta de unas 300.000 personas. 


\section{TIPOS Y CAUSAS DE LAS EMIGRACIONES}

El fenómeno migratorio, aunque persistente en el tiempo, adopta continuamente nuevas formas atendiendo a cuatro variables principals: procedencia, destino, duración y causa que las provoca.

Si atendemos a la primera cabe diferenciar entre áreas rurales y urbanas, áreas meridionales o de interior y áreas septentrionales o costeras, migración joven e individual y migraciones familiares, procedentes de la agricultura o la ganadería o de actividades del sector secundario o terciario, sin cualificar o medianamente cualificada, masculina o femenina, es decir, multitud de posibilidades que responden a la enorme variedad, al gran paraguas bajo el que se cobija un hecho en general poco deseado, cual es el abandono, temporal o permanente del lugar $\mathrm{d}$ e origen para buscar unas mejores condiciones de vida en otro lugar.

Algo semejante podriamos decir de las migraciones en razón de su destino (interiores y exteriores), de su duración (estacionales, polianuales o definitivas) y sus causas (políticas y económicas principalmente).

Aunque este fenómeno tiene mayor importancia en los últimos diez años, especialmente en lo que hace referencia a nuestro país, la emigración norteafricana hacia Europa es ya un proceso tradicional, como recoge B. LÓPEZ (95): "Las migraciones contemporáneas norteafricanas a Europa tienen una prehistoria que data de los origenes de la colonización, sobre todo en Argelia, que trastocó las estructuras tradicionales y contribuyó a producir grandes movimientos humanos interiores y exteriores".

El tipo medio de emigrante magrebí hacia Europa ha ido modificándose y diversificándose con el tiempo, pero también en razón de los países receptores. En cualquier caso destacan dos hechos:

- El elevado número de mujeres jóvenes que individualmente o en grupos familiares han llegado, primero a las ciudades (industria textil, empleadas de hogar, etc.) y luego como temporeras en actividades de recogida de fruta (Lérida, Levante, etc.).

- El notable volumen de familias completas que se desplazan o que a través de la recuperación familiar acaban asentándose en los países receptores.

Esto no es óbice para que el predominio siga siendo de población joven y masculina, pero un gran número de cabezas de familia, una vez consiguen una vivienda y un trabajo fijo (industria, construcción, etc.) llaman a sus familias, con el ánimo de permanecer indefinidamente en el país o al menos una buena serie de años. La vinculación con el lugar de origen se mantiene viva, con encuentros de emigrantes, fiestas religiosas, vida social y especialmente el vivificante pero agotador viaje de vacaciones que hace que en los meses de julio y agosto atraviesen España hasta un millón de viajeros, que encuentran su cuello de botella en el dificil paso del Estrecho o en los puertos andaluces.

Estos viajes no sólo mantienen vivas sus señas de identidad sino que actúan como estímulo para el viaje de otros potenciales emigrantes en un clarísimo efecto de llamada. Cabría prever que, como ocurriera en la España de los 70, tras unos años de estancia en los países desarrollados y una vez conseguida una cierta cantidad de dinero, se produjese el retorno al país de origen. Puede que esto sea lo que en el futuro ocurra y también que éste sea el deseo 
intimo de los emigrantes, pero la ausencia de expectativas económicas, sociales, educativas y políticas hacen que esta población se asiente en el país de acogida de manera definitiva. Una mejora en general de la situación de esos países podria hacer retornar a parte de esa población y así convertirse en un auténtico motor de cambio y dinamizador de la sociedad magrebí. Por el momento, estas posibilidades son más especulaciones que realidades.

En cuanto a las causas son, como en casi todos los lugares, muy variadas, tanto estructurales o generles como individuales. Agotamiento de las tierras, incrementos demográficos, ausencia de libertades cívicas, caciquismo, paro, dificultades para acceder a una mejor educación, trabajo, vivienda, etc. y muchas otras son el consabido corolario, además de la ya citada situación política argelina. Entre tanto panorama negativo, la llegada al trono marroquí de Mohamed VI ha creado grandes expectativas sobre cambios profundos, de los que tan necesitado se encuentra el pais.

Entre 1980 y el año 2000 el incremento anual medio de la población ha sido del $2,5 \%$ en Argelia y 2,0\% en Marruecos y Túnez, mientras que la población activa (es decir, la competencia en busca de puestos de trabajo escasos y mal remunerados) ha crecido a un ritmo superior: Argelia 3,8\% anual; Marruecos, 2,6\% y Túnez, 2,8\%.

Actualmente, la población del Magreb (sin tener en cuenta los aportes que recibe de otros países africanos, especialmente del Sahel y del golfo de Guinea) se incrementa cada ño en 1,4/1,5 millones de personas. Si tenemos en cuenta que la U.E., principal receptor de estos emigrantes está recibiendo, de forma legal o ilegal a unos 250.000 emigrantes por año, observaremos la situación explosiva que se está generando en la orilla sur del Estrecho. Además, nada garantiza que el incremento de esta corriente migratoria en los tres últimos años -y la competencia con la procedente de los países del Este de Europa y los Balcanesse mantenga indefinidamente, pues la U.E. está dispuesta a regularla y reducirla, con lo que España puede edurecer aún más sus controles de esta zona, con el fin de que en tres o cuatro años quede totalmente impermeabilizada y sólo exista la emigración oficial, controlada cuantitativamente y también en la cualificación, sexo, edad, formación, etc.

Los intereses de la U.E. se contraponen, sin embargo, a las necesidades de los países del Magreb (y también, por supuesto, al resto de los paises de África, que ven en la corriente migratoria casi su única esperanza de escapar de la miseria o de la muerte). Por eso, como señala H. SAYED (1993), la migración internacional es para estos paises "un instrumento para aliviar la presión del alto crecimiento de la población y consideran esenciales las remesas de los emigrantes para mejorar sus condiciones económicas y productividad, mientras afrontan el problema de la fuga de cerebros y de la selectividad de la migración".

Por tanto, es claro que los países emisores aceptan que esa corriente empobrecerá intelectualmente el país, despojándolo de técnicos superiores y medios, a cambio de aliviar la presion demográfica e ingresar divisas que, desgraciadamente, no se invierten en mejorar sustancialmente las infraestructuras que permitan matener a estos cuadros técnicos imprescindibles si se quiere propiciar el desarrollo del país.

$\mathrm{Y}$, si atendemos al capítulo de las divisas remitidas por los emigrantes, baste decir que los marroquies residentes en Europa enviaron a su pais 1.888 millones de dólares, en 1997 , 2.014 millones den 1998 y 1.877 millones en 1999, es decir, más del 6\% del PNB del país. 
Ésta es incluso algo superior a la ingresada por la actividad turística, en cuyo desarrollo tiene puestas buena parte de sus esperanzas, y algo parecido ocurre con Túnez.

\section{CONSECUENCIAS DE LA MOVILIDAD GEOGRÁFICA DE LA POBLACIÓN}

El proceso que significa el desplazamiento de masas importantes de población, ya sea como reordenación de la distribución geográfica de ésta dentro del propio país o a la marcha a otros paises, ya sea con carácter temporal o definitivo y teniendo en cuenta también todos los demás caracteres (causas, composición, etc.), tiene enormes repercusiones en todos los ámbitos de la vida de ese país.

Si atendemos a las migraciones exteriores se observa cómo los países receptores van reaccionando -y casi nunca con generosidad o simplemente con justicia- al aumento progresivo en la llegada de estos pueblos, pertenecientes a culturas, lenguas, modos de vida e incluso religión diferentes.

Durante bastantes años los paises que actualmente forman parte de la Unión Europea, especialmente Francia, y en menor proporción Bélgica, Holanda, Italia, Alemania y España, han acogido lo que podríamos llamar excedentes demográficos magrebies, además de un no pequeño número de refugiados políticos. Han constituido comunidades estables, familiares en muchos casos, y perfectamente integradas en el pais de adopción, aunque también claramente diferenciadas, ya que han mantenido ciertos rasgos propios, especialmente los religiosos y los de comportamiento social.

Sin embargo, vienen a coincidir en el tiempo de radicalización de los grupos políticos, minoritarios pero muy activos, que hacen de la xenofobia y el racismo su bandera de enganche y de justificación de casi todos los problemas que afectan a las zonas urbanas, con altos índices de paro, de inseguridad o de malestar social.

Capítulos tan lamentables como los vividos en Alemania, Francia o España, donde bandas de "skin heads" han hecho de la persecución al inmigrante su única justificación vital (jaleados y auspiciados por movimientos ultraderechistas casi siempre). La caza al extranjero o más bien al diferente, moro, turco, negro, etc., según los países o las regiones, es uno de los espectáculos más deprimentes de la desarrollada Europa.

El número de incidentes es tanto mayor cuanto más se incrementa el volumen de emigrantes, mayor es la concentración espacial y existe mayor temporalidad en esta emigración (temporeros o migrantes estacionales). La migración estacional es absolutamente imprescindible para ciertas actividades que necesitan una gran cantidad de mano de obra sin cualificar, pero es dificil de integrar, tanto por su propia estacionalidad como por la intensidad del trabajo en esta época, la composición de esta población (casi exclusivamente joven y masculina), e incluso el trato económico y social muy discriminatorio que suelen recibir. En realidad el trato que reciben los temporeros del campo almeriense, levantino u onubense no es muy distinto del que hace unos años recibian los españoles que iban a Francia para hacer la vendimia, pero esto no puede ser una justificación, sino más bien un acicate para no cometer iguales o parecidos errores. 
Por otra parte, el espectacular crecimiento de las migraciones exteriores, el amplio tratamiento que se ha hecho por parte de los medios de comunicación de las tragedias, de los enfrentamientos, de los problemas que genera (El Ejido, Barcelona, barrio de Lavapies, en Madrid, por citar algunos ejemplos recientes en España, pero también los problemas de integración escolar de los niños marroquíes), nos puede hacer olvidar que, numéricamente, el principal embate de la corriente migratoria lo sufren las propias ciudades de cada país del Magreb.

En efecto, la mayor parte de esta corriente migratoria, recala en las ciudades costeras o en algunos puntos del interior, agravando los problemas que ya tenían previamente y además significando el abandono de ciertas áreas del sur, en los límites con el desierto o la montaña.

Se da así la situación de que siglos de lucha ancestral contra el avance del desierto y de adaptación a un medio tremendamente hostil, en cuya relación han surgido formas de vida y culturas ancestrales y peculiares, van casi a desaparecer en un periodo muy breve y donde quedarán pequeños retazos adulterados de éstas, con fines casi de ecomuseo o puramente de atracción turística.

El ya citado H. SAYED (1993) recoge las estrategias diseñadas por estos países en relación con el fenómeno migratorio y el impacto de éste sobre áreas ya muy pobladas, buscando así un reajuste en la distribución espacial de la población:

“a) Retardando el crecimiento de la ciudad y sus áreas metropolitanas.

b) Promocionando las ciudades pequeñas y medias y construyendo nuevas ciudades.

c) A través del desarrollo rural y estrategias que conduzcan a reformas agrarias y de la mejora de la infraestructura básica en estas áreas.

d) Asegurando el desarrollo equilibrado de las regiones del pais.

e) Asentando a los nómadas y adoptando esquemas de colonización para incrementar las áreas agrícolas productivas."

Realmente, más que unas estrategias específicas parecen unas ideas generales o unos deseos, pero sin concretar de qué manera se pueden conseguir, de tal modo que tal vez tengan más de utopía que de realidad. Siguiendo ese mismo orden podríamos argumentar:

a') Las tres grandes áreas metropolitanas del norte de África, Casablanca (4 millones de habitantes), Argel (3,7 millones) y Rabat-Salé ( 2 millones) agrupan a la séptima parte de la población, en un territorio de unos 3 millones de $\mathrm{km}^{2}$. Si añadimos las áreas metropolitanas con más de medio millón de habitantes tendriamos una quinta parte de la población total.

b') Algunas de las llamadas ciudades medias ya no son tales, puesto que han pasado a poseer más de medio millón de habitantes (Oujda, Agadir, Constantina, etc.) y so concentración ha sido tan vertiginosa que provoca gravísimos problemas de vivienda, trabajo y relación. En cuanto a las ciudades nuevas, se trata más bien de barrios o ciudades satélites en el entorno de las capitales.

c') Las áreas rurales han incrementado fuertemente su productividad con una agricultura intensiva, cultivos forzados, riego, utilización abudante de fertilizantes, espe- 
cialmente de fosfatos (de los que Marruecos y Túnez son el $2^{\circ}$ y $4^{\circ}$ productores mundiales, respectivamente), en gran medida con capital extranjero. También la infraestructura ha mejorado, pero partiendo de unos niveles casi inaceptables, por lo que el acceso al agua potable, la mejora en la atención sanitaria y las comunicaciones son logros evidentes pero insuficientes.

d') El equilibrio propuesto es una utopia, pues precisamente estas migraciones rompen cualquier posibilidad al respecto $y$, por otra parte, los gobiernos están más interesados -tal vez obligados por la situación existente y su evolución- en el crecimiento económico que en el desarrollo sostenible, es decir, primero vida, y luego calidad de vida.

e') $\mathrm{El}$ asentamiento de nómadas no es irrelevante, pero cada vez tiene menor contenido en importancia, ya que tal población es escasa y la propia dinámica económica y social ha ido reduciendo su volumen y significación.

La incidencia del aumento de su población, ya sea debido al crecimiento natural, ya a los flujos migratorios (propios o ajenos), sobre un medio geográfico ya muy afectado por el avance del desierto, es un hecho que puede adquirir caracteres dramáticos. Algunos de los más importantes, de tipo medioambiental, son:

- Contaminación. Del agua, del aire en las densas zonas urbanas, con escasez de politicas de protección ambiental, o en las áreas industriales.

\section{Cuadro 3}

La educación en el Magreb

\begin{tabular}{|c|c|c|c|c|c|c|}
\hline \multicolumn{7}{|c|}{ Analfabetismo (mayores de 15 años) } \\
\hline & & 1980 & 1985 & 1990 & 1995 & 2000 \\
\hline ARGELIA & & $59,9 \%$ & $53,2 \%$ & $47,2 \%$ & $41,6 \%$ & $36,7 \%$ \\
\hline MARRUECOS & & $71,4 \%$ & $66,5 \%$ & $61,3 \%$ & $56,0 \%$ & $51,1 \%$ \\
\hline TÚNEZ & & $53,2 \%$ & $47,3 \%$ & $40,9 \%$ & $35,5 \%$ & $29,2 \%$ \\
\hline \multicolumn{7}{|c|}{ Enseñanza Superior (Estudiantes) } \\
\hline & $1970 / 71$ & 1975/76 & 1980/81 & 1985/86 & $1990 / 91$ & 1995/96 \\
\hline ARGELIA & 19.531 & 41.847 & 79.351 & 132.057 & 298.117 & 347.410 \\
\hline MARRUECOS & 16.097 & 45.322 & 112.405 & 181.087 & 255.667 & 311.743 \\
\hline TÚNEZ & 10.347 & 20.505 & 31.827 & 41.549 & 68.535 & 121.787 \\
\hline \multicolumn{7}{|c|}{ Gastos totales en educación (\% P.N.B) } \\
\hline & 1970 & 1975 & 1980 & 1985 & 1990 & 1996 \\
\hline ARGELIA & $7,9 \%$ & $6,7 \%$ & $7,8 \%$ & $8,5 \%$ & $5,5 \%$ & $5,1 \%$ \\
\hline MARRUECOS & $3,5 \%$ & $5,3 \%$ & $6,1 \%$ & $6,3 \%$ & $5,5 \%$ & $5,3 \%$ \\
\hline TÚNEZ & $7,1 \%$ & $5,2 \%$ & $5,4 \%$ & $5,8 \%$ & $6,2 \%$ & $7,7 \%$ \\
\hline
\end{tabular}

FUENTE: Anuario Estadistico de la UNESCO, 1999. 
- Agotamiento de los recursos hídricos.Por sobreexplotación de unos acuíferos escasos y que no tienen tiempo de reponerse o por el propio avance del desierto, fenómeno que afecta a todos los países colindantes.

- Agotamiento de las tierras. Por el incremento de la población que provoca el sobrecultivo, la desaparición del barbecho, los cultivos esquilmantes y grandes consumidores de agua, pero muy demandados en las ciudades (hortalizas, frutas, etc.).

- La destrucción de la cobertera vegetal. Con el cultivo de tierras marginales, la ganadería extensiva (especialmente ovina y caprina), el consumo de madera, etc.

Una esperanza real es la mejora en los aspectos educativos, especialmente la elevación en el número de estudiantes de enseñanza superior y el descenso notable del analfabetismo, aunque las cifras actuales son todavía muy preocupantes, como se observar en el cuadro n." 3 .

\section{CONCLUSIONES}

1. La población magrebí tiene ya un volumen considerable (70 millones), pero las previsiones la sitúan hacia el año 2025 en 100 millones. Si no mejora la situación en la región, en todos los aspectos, será un auténtico polvorín en las puertas de Europa.

2. África del Norte, y especialmente Marruecos, es una plataforma de acceso a los paí. ses de la Unión Europea.Históricamente se ha comportado como puente de intercambio y de flujos culturales y demográficos entre los dos continentes y su cierre nos retrotraería a situación propias de otra época histórica y a un enfrentamiento radical muy peligroso. Para el resto de África esta zona es "mitad de etapa", pero la dificultad de continuar hacia Europa puede concentrar aquí un elevado número de emigrantes del Sahel y del golfo de Guinea, provocando mayores problemas internos.

3. Es imprescindible establecer alternativas a toda esta cadena de la emigración, no solo creando puestos de trabajo en los países emisores, sino sobre todo propiciando una situación política, económica y social en estos puntos de salida, que haga innecesaria la solución migratoria.

4. Las soluciones para paliar todos estos problemas no pueden ser impuestas, sino que deben realizarse de acuerdo con las peculiaridades y los intereses generales de las regiones afectadas. En caso contrario se mostrarán ineficaces y solamente retardatorias del proceso.

5. La educación, la formación técnica, el incremento de las ayudas en infraestructuras son elementos básicos para conseguir el desarrollo de estos países.

6. Grandes lacras politicas y sociales, como el integrismo religioso, la situación social de la mujer, el caciquismo, las tremendas desigualdades sociales, las diferencias raciales internas, la ausencia de sistemas democráticos modernos, son asuntos estructurales y no coyunturales, en el camino para el desarrollo.

7. La creación de nuevos centros o actividades económicas debe servir para aliviar y no concentrar aún más la presión sobre ciertas áreas urbanas superpobladas. 
8. El turismo puede ser uno de los motores de crecimiento económico de estos países. La mejora de las infraestructuras, de las comunicaciones, etc. pueden convertir al Magreb en uno de los focos de atracción de unos países ricos y viajeros, situados de una a tres horas de vuelo. Por otra parte, una buena comunicación fija por el Estrecho sería la mejor noticia para toda la zona.

9. El cambio climático afecta a todos los lugares, pero las áreas más sensibles, somo los bordes del desierto, son las que más están sufriendo. Sin una política adecuada sobre el uso de los recursos (agua, tierra, vegetación, contaminación ambiental, etc.) se pueden producir epidemias, enfermedades sociales, etc. y un deterioro general del medio y de la población.

10. La posición clara de los políticos y de los ciudadanos de los países de la Unión Europea debe erradicar los conflictos de xenofobia y racismo, puntuales pero terribles y cada vez más extensos, dentro de su territorio. Además, el norte de África está llamado a convertirse en un tiempo más o menos breve, en un aliado estratégico -tal vez incluso miembro- de la Unión Europea. El reconocimiento de la necesidad mutua de entendimiento debería llevar a aliviar tensiones y solucionar muchos problemas que, en caso contrario adquirirán dimensiones de dificil salida. H.LE HORÉOU (992) lo expresó con rotundidad:

"A menos que se tome una fuerte y decidida acción entre ahora y el año 2050, la catástrofe es aritméticamente inevitable. El malestar social y todaclase de extremismo podria florecer. Los paises europeos podrian sufrir una presión extrema por parte de las hambrientas multitudes del Sur. Tales presiones podrian conducir a un malestar social, racismo y, es temer, regimenes politicos totalitarios. Los sintomasya están presentes en algunos paises".

Han pasado 8 años y los síntomas son realidades. Es preciso tomar medidas correctoras y aplicarlas ya.Las soluciones pasan por el presente si queremos que el futuro sea mejor, y tanto Europa como el Magreb deben trabajar para conseguirlo.

\section{BIBLIOGRAFÍA}

BARRIENTOS ALFAGEME, G. (1999): “Cooperación e integración en el Mediterráneo”, en Hacia un nuevo espacio Euromediterráneo.AGE, Barcelona.

BEL DEL, C. y GÓMEZ FAYREN, J.(1959): “Migraciones y cooperación al desarrollo", en Haci aun nuevo espacio Euromediterráneo. AGE, Barcelona.

DOMINGO, C y GOZÁLVEZ, V. (1996): La inmigración magrebi en España: actualidad y futuro. Boletín de la AGE N. ${ }^{\circ} 23$, Madrid.

ECHEVARRÍA, C. (1999): El Magreb y sus problemas. Rev. Estudios Africanos n. ${ }^{\circ} 24$, Madrid.

LACOSTE, Y. (1997): Geopolitique d'une Afrique Mediane. Rev. Herodote, n. "86, París. 
LE HOURÉOU, H. N. (1992): "Vegetation and Land use in the Mediterranean Basin by de Year 2050: A Prospective Study", en Climate Change and the Mediterranean, Arnold, Nueva York.

LÓPEZ GARCÍA, B. y otros (1993): Inmigración magrebi en España. El retorno de los moriscos, Mapfre, Madrid.

LÓPEZ GARCÍA, B. (1995): "Visión española de la inmigración norteafricana a Europa", en Cooperación Cultural en el Occidente Mediterráneo, Fundación BBV-U. CastillaLa Mancha, Fundación Europea de la Cultura, Barcelona.

LÓPEZ, B., PLANET, A.I. y RAMÍREZ, A. (1996): Allas de la emigración magrebi en España. Dirección General de Migraciones, U. Autónoma de Madrid, Madrid.

MARQUINA, A. (Ed.) (1997): Flujos migratorios norteafricanos hacia la Unión Europea, A.E.C.I., Madrid.

MCMICHAEL, A. J. y otros (1996): Climate Change and Human Health, O.M.S., Ginebra.

O.N.U. (1999): Anuario demográfico 1998, Nueva York.

SAYED, H. (1993): Review of Population Policies: Northern Africa and Wertern Asia, United Nations, Nueva York.

SID AHMED, A. (1997): El Mediterráneo, de la integración a la fragmentación, Cidob/Icaria, Barcelona.

TORRES LUNA,P. de (1996): Africa. Reflexión geográfica sobre su población y compartimentación regional, Rev. Espacio, Tiempo y Forma, UNED, Madrid.

UNESCO (2000): Anuario Estadistico 1999, París.

ZAIIM, E. y JAIDI, L. (1997): El acuerdo de asociación entre la U.ee. y Marruecos, I.C.E. n." 759 , Madrid.

CALENDARIO ATLANTE DE AGOSTINI, ENCYCLOPEDIA BRITANNICA, EL ESTADO DEL MUNDO (Varios años). 